\title{
Caclulation Structure of Labor Costs for the Research and Development
}

\author{
Sergey Novikov ${ }^{1} \&$ Andrey Sazonov $^{1}$ \\ ${ }^{1}$ Moscow Aviation Institute (National Research University), Moscow, Russian Federation \\ Correspondence: Sergey Novikov, Moscow Aviation Institute (National Research University), Moscow, 4, \\ Volokolamskoe Highway, 125993, Russian Federation. Tel: 7-963-753-7110. E-mail: danonik92@mail.ru, \\ ncsrm@mail.ru
}

Received: February 17, 2020

Accepted: March 23, 2020

Online Published: June 16, 2020

doi:10.5430/rwe.v11n3p50

URL: https://doi.org/10.5430/rwe.v11n3p50

\begin{abstract}
The article is devoted to labor costs standards determination method for the preparation, organization and implementation of research and development (R\&D). Labor costs norms and standards areas of use for R\&D are defined. In the methodological part of the article, there is a proposed schematic representation of the calculating process of the labor intensity normative indicator. During the study, it was found that the number of communication possible forms between the change in the labor costs volume and the change in the standardized planning and accounting unit and analogue factors is limited to three, according to which calculation formulas for particular comparability coefficients are given in the article. The discussion in the article is based on features discussion of using experimental statistical and expert methods for determining standard indicators for labor costs comparing standard indicators.

The result of the study is the multilateral algorithm development for determining the labor costs normative volume for a standardized object based on the use of two possible scenarios. In conclusion it was note that one of the ways to increase the determining efficiency of R\&D cost is to further improve the legislative and normative-methodological framework for conducting this assessment, creating incentives for work performers to reduce costs with R\&D quality necessary level, for example, by keeping them parts of the resulting savings.
\end{abstract}

Keywords: labor costs standards, R\&D organization, optimization of research, labor costs calculation methodology in the field of $R \& D$

\section{Introduction}

Russian enterprises are slowly but surely moving away from the traditional model of Soviet R\&D, when everything from start to finish was developed in the bowels of a single enterprise or industry research institute. Today, more and more companies are outsourcing business hypothesis testing. The forms of external cooperation can be very different: either they are their subsidiaries, which are exclusively engaged in R\&D, or cooperation with research institutes or higher specialized educational institutions, in the laboratories of which the idea is under challenge. Recently, enterprises began to actively outsource their rather narrow and practical tasks solution to educational institutions: Moscow State University, Moscow Engineering Physics Institute, Moscow Institute of Physics and Technology, Moscow Aviation Institute, and "Skoltech" (Skolkovo Institute of Science and Technology). At the same time, they continue to actively use both internal R\&D and R\&D institutes' developments. This new trend did not exist just five years ago. So far, large corporations and concerns having their own developed research base have chosen this path. Among this model advantages is the ability to quickly test ideas without investing in staff training and building up the laboratory base. Among the model's shortcomings is the inability to implement a full-fledged mechanism for monitoring the intellectual activity results and the opportunity to focus on the commercial result not always exists. Russian enterprises that invested money and were able to bring the business hypothesis to a commercial result, with their successes prove that innovation is a springboard for the growth and development of the enterprise (Durnev \& Zhdanenko, 2013).

The research organizations' performance indicator in modern economic realities, as a rule, is directly dependent on the optimization degree of current costs per labor organization, and is also associated with the possibility of improving methods for determining labor intensity indicators. Consequently, if a company lacks high-quality and effective labor rationing, then in principle it is not possible to plan work correctly, evaluate and stimulate workers, and it is impossible to realize significant growth in the field of labor productivity, as well as reduce time for developing and implementing advanced innovative technologies into existing enterprise production cycle. Modern 
domestic design bureaus, research institutes and other organizations which activity profile is related to R\&D have to necessarily lead to the process of developing a system related to labor standards in order to increase general labor productivity indicators at the enterprise, as well as labor resources use degree.

\section{Theoretical Basis}

In the field of R\&D, as well as in other labor areas, there is a law of diminishing effectiveness. This law basis is the provision that if there is a significant increase in labor costs, at which other costs value increases, then a situation appears in which any additional labor amount will make a smaller contribution to the total labor result. The existing connection between the labor expended amount and the result in the R\&D implementation is not constant and may be subject to certain changes that are cyclical in nature, which to some extent is associated with a change in the stages sequence of technical and scientific areas implementation. The process of $R \& D$ involves the allocation of the following research stages (Bokov, \& Podolsky, 2015):

- unique technological principle emergence;

- ability to achieve a specific technological implementation;

- ability to achieve a certain indicator of traditional technology economic efficiency;

- achievement of a certain limit associated with a further increase in the performance indicators of the updated equipment within the existing principle.

Research work consists not only in the search and subsequent finding of the necessary methods and means necessary for the high-quality satisfaction of the society's existing practical needs, but also makes it possible for enterprises' employees to satisfy their intellectual needs. Creative interest in the search and subsequent solution of a real problem is a rather significant factor, to some extent subjective, but able to quickly increase the level of scientific work productivity, and as a result, reduces its labor intensity. Therefore, there are some restrictions imposed on the use in the work of straightforward approach enterprises in terms of calculating the necessary amount of time that should be spent on organizing R\&D. The opportunity to continue to do research work after the end of the working day leads to the fact that the length of officially spent working time does not reflect the actual labor costs of the researcher (developer), which means that certain labor costs standards for research taking into account these features are needed (Dmitriev \& Novikov, 2019).

The labor costs system of standards and norms for R\&D is the main element of the regulatory framework for planning labor costs for R\&D. Under the regulatory framework is understood the labor costs system of standards and norms totality for R\&D of reference information necessary for the development and improvement of organizational, administrative and normative-methodical documentation standards and norms, providing a unified procedure for the creation, implementation and improvement of standards and norms and unified methodological approach to the development and use of standards.

Labor costs standards and norms for research (R) and development (D) are classified according to the following criteria (Anikeichik, Kinzhagulov \& Fedorov, 2016):

- application object group;

- aggregation level of constituent elements (CE) of R\&D;

- type of work;

- approval level;

- development method and validity.

The procedure for the development and use of standards and labor costs for R\&D is a systematic process of rationing labor costs for research, development the work performed in their composition. It includes two main stages (Abramova, Abramov \& Kornilova, 2015):

- standards development;

- standards use and adjustment.

The R\&D classification basis is a set of criteria on the basis of which classifiable objects are evaluated and a decision is made on whether they are assigned to one or another classification group. For R\&D carried out in order to create radio-electronic equipment (RE), in addition to the specified criteria, criteria are used to evaluate the functional-targeted, structural and technological features of the developed RE (objects under study) and to classify the objects of development (research). To classify development objects, as a rule, the following classification features are used (Novikov, 2019): 
- functional-targeted: subclass of RE, group of RE, subgroup of RE, type of RE;

- constructive: RE disaggregation level, parametric series, features characterizing novelty: principles and parameters, design, electronic components and materials;

- technological: necessary technology, production volume.

The standards and norms classification by application objects groups is carried out by assigning them to adequate classes of research (development) objects. The research (development) objects grouping is carried out in accordance with the methodological recommendations for the R\&D classification presented in theTable 1.

Table 1. Classification features characteristics composition and description

\begin{tabular}{|c|c|}
\hline Feature title & Feature characteristic \\
\hline \multirow{2}{*}{ Application object group } & Research objects classification groups \\
\hline & Development objects classification groups \\
\hline \multirow{2}{*}{$R \& D C E$ aggregation level } & Stage \\
\hline & Step \\
\hline \multirow{4}{*}{$R \& D C E$ aggregation level } & Sub-stage \\
\hline & Work \\
\hline & Procedure \\
\hline & Operation \\
\hline \multirow{17}{*}{ Type of work } & System \\
\hline & Schematic \\
\hline & Design \\
\hline & Technological \\
\hline & Mathematical and software \\
\hline & Standardization and unification \\
\hline & Reliability assurance \\
\hline & Metrological support \\
\hline & Feasibility study \\
\hline & Technical documentation ensuring \\
\hline & Patenting and invention \\
\hline & Scientific and technical information providing \\
\hline & Models and prototypes production \\
\hline & Models and prototypes testing \\
\hline & Implementation D results \\
\hline & Theoretical and experimental research providing \\
\hline & Scientific organization of labor \\
\hline \multirow{3}{*}{ Approval level } & Intersectoral \\
\hline & Industry \\
\hline & Enterprises \\
\hline \multirow{2}{*}{ Development methods } & Expert \\
\hline & Experimental Statistical \\
\hline \multirow{2}{*}{ Validity } & Stable \\
\hline & Temporary \\
\hline
\end{tabular}

The standards and norms classification by the R\&D CE aggregation levels is based on the planning and accounting units classifier. The standards and norms classification by type of work is carried out on the basis of a planning and accounting units classifier, which allows to establish whether the standardized work belongs to one or another type of work, the list of which is given in the Table 1. The standards classification by approval levels is based on a hierarchical principle (Avdeeva, Polyanin, \& Golovina, 2019): 
- $\quad$ intersectoral standards;

- $\quad$ industry standards;

- local regulations.

Intersectoral and industry standards are divided into uniform and standard. The division of intersectoral and industry standards into uniform and standard is determined by their scope (Novikov \& Veas Iniesta, 2019):

- uniform standards are developed at R, D and R\&D CE, which are carried out according to the same technology and in similar organizational and technical conditions in a number of national economy sectors or in one industry;

- typical standards are developed at R, D and R\&D CE, which are carried out according to standard technology, taking into account the progressive organizational and technical conditions that already exist in most or part of enterprises where such developments are carried out.

Local standards are developed in the absence of appropriate intersectoral or sectoral, as well as when the company creates more advanced organizational and technical conditions for R\&D as compared with those available when developing intersectoral and industry standards (Yashin, \& Grigoryan, 2015).

The standards classification by the development method is carried out in accordance with which of the methods regulated by this working document (WD), expert or experimental-statistical is used to obtain and process the source data in the standards development. Standards must satisfy the progressiveness requirements, reliability, comparability, and interoperability. The standards progressiveness is understood as their orientation toward the advanced techniques and methods use for achieving the stated goal and organizational and technical conditions for carrying out R\&D in the performing R\&D process. The standards progressiveness is supported by their systematic updating (adjustment) based on the factors consideration of scientific and technological progress, advanced methods of organizing R\&D as well as labor organization. The standards reliability is understood as the compliance degree of the standards established values with the labor costs volume, objectively necessary to perform work on a standardized planning and accounting unit with a given quality. Reliability is ensured by features objective consideration of research, development and the organizational and technical support level of R\&D. Comparability refers to the possibility of comparing labor costs standards for similar planning and accounting units performed by various departments or various enterprises. Comparability is ensured by the unified industrial R\&D CE classification, a unified information base and the unified methodology use for developing the standards. By the standards compatibility, there is understood a coordination according to the R\&D CE aggregation levels. R\&D labor costs standards and norms areas of use are given in the Table 2.

Various methods are proposed for R\&D standardization, because of R\&D processes differences. Compared with research, the development process is much more deterministic and allows connecting the research labor costs with the developed RE technical parameters and the organizational and technical conditions for research. Many identical elements existence in different developments, the developments' continuity and their certain repeatability (constructing RE parametric series products possibility) make it possible to accumulate statistical data on development's labor costs and individual development elements (Durnev \& Zhdanenko, 2013).

Table 2. R\&D labor costs standards and norms areas of use

\begin{tabular}{|c|c|c|c|c|c|c|}
\hline \multirow{5}{*}{$\begin{array}{l}\quad \text { R\&D } \\
\text { components } \\
\text { aggregation } \\
\quad \text { level }\end{array}$} & \multicolumn{6}{|c|}{ Standard's approval level } \\
\hline & \multicolumn{3}{|c|}{ Sectoral, enterprises } & \multicolumn{3}{|c|}{ Sectoral } \\
\hline & \multirow{2}{*}{\multicolumn{3}{|c|}{ Operational scheduling }} & \multirow{3}{*}{$\begin{array}{l}\text { Planning system } \\
\text { Current (annual) } \\
\text { planning }\end{array}$} & \multirow{3}{*}{$\begin{array}{c}\text { Perspective } \\
\text { (five-year) planning } \\
\text { on enterprises' topics }\end{array}$} & \multirow{3}{*}{$\begin{array}{l}\text { Result-oriented } \\
\text { planning }\end{array}$} \\
\hline & & & & & & \\
\hline & $\begin{array}{l}\text { of structural } \\
\text { departments }\end{array}$ & $\begin{array}{l}\text { of structural } \\
\text { units }\end{array}$ & $\begin{array}{c}\text { on } \\
\text { topics }\end{array}$ & & & \\
\hline Stage & - & - & + & + & + & + \\
\hline Step & - & - & + & + & + & + \\
\hline Sub-stage & - & - & + & + & + & + \\
\hline Work & + & + & + & - & - & - \\
\hline Procedure & + & + & + & - & - & - \\
\hline
\end{tabular}

Note. Legend:

«+» means R\&D element used in this planning system;

«-» means R\&D element not used in this planning system. 
In the study's framework, it is proposed to use a methodology that assumes that the necessary labor intensity establishment at the detailed design stage is possible while taking into account expert studies of various factors groups' use that are pre-formed and implemented into a specially developed process model. The recommended methodology makes it possible to conduct an expert study of labor intensity certain components in order to determine the impact degree on them that they make on current labor process structure and time. The methodology provides the opportunity to identify those factors from the general group which influence degree varies according to the main research process sub-stages. Using the recommended methodology involves dividing the process of detailed design into sub-stages (Abramova, Abramov \& Kornilova, 2015):

- preliminary design;

- design coordination and working drawings production.

\section{Methodology}

When conducting an individual experts and specialists survey, the values accepted by factors are usually measured from 0 to 2.0, and the values of the factors force in the sub-stages vary in the intervals from 0 to 1.5. The survey is carried out on the product-analogue and the designed product. The schematic normative labor intensity indicator process calculation is represented in the Figure 1.

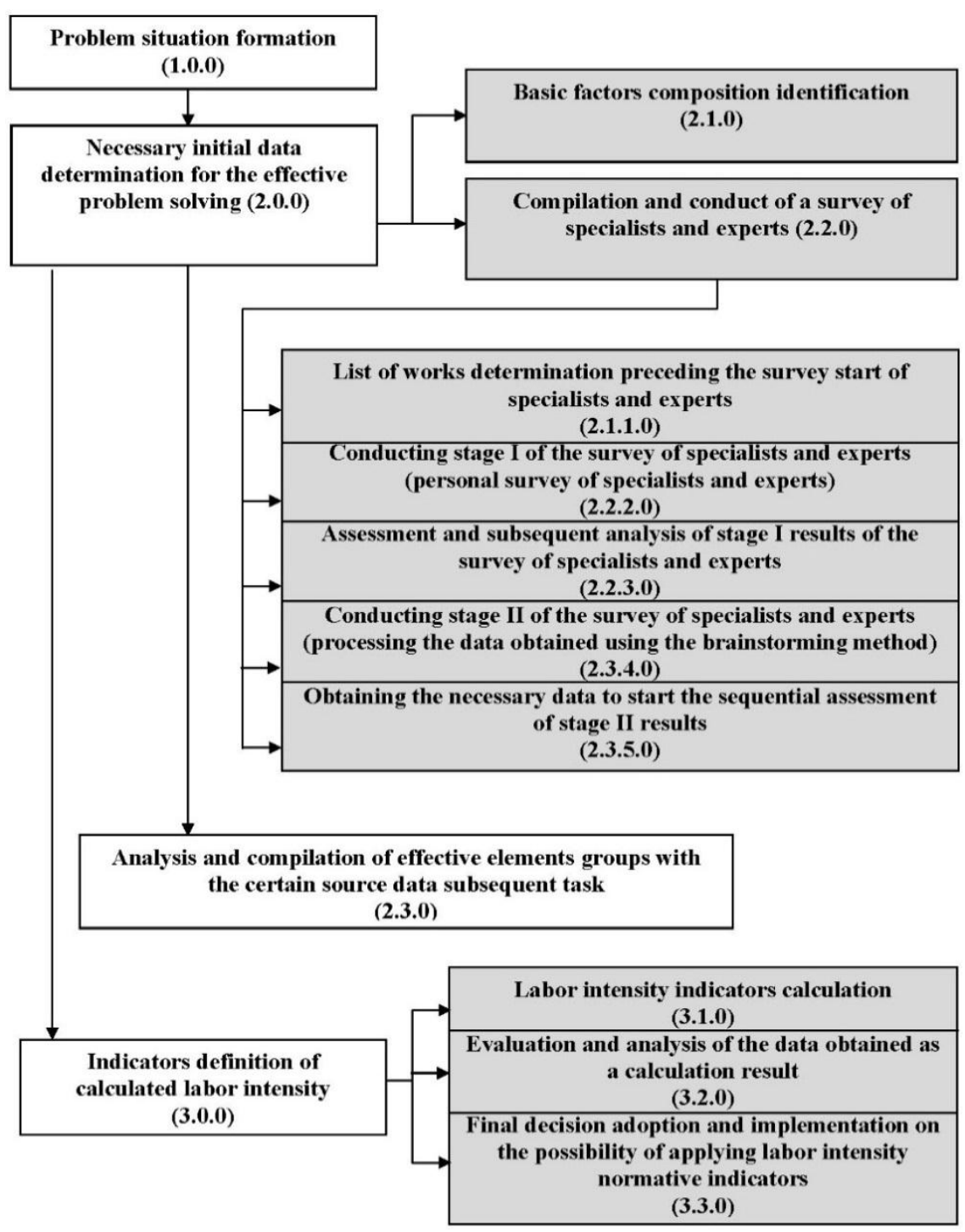

Figure 1. Schematic representation of the labor intensity normative indicator calculating process 
After the first examination stage, the assessments obtained are analyzed in order to determine the resulting assessment and the consistency degree of expert opinions, to identify conflicting assessments. The second stage of the expert survey gives an assessment of the examination's first round results objectivity. At the same time, controversial issues are resolved according to conflicting estimates. After the second stage of the expert survey, the resulting table is compiled (Dmitriev \& Novikov, 2019).

The most typical methods for calculating the labor intensity of complex science-intensive products manufacturing are the method of reducing the absolute labor intensity by the same percentage for each doubling of products manufactured from the beginning of production and the method of reducing the absolute labor intensity of the same percentage for each doubling of the product range daily output. If the first product's manufacturing labor intensity is denoted by the letter $T_{1}$ and the product number $\mathrm{N}$ labor intensity, issued from the beginning of production, by the letter $T_{N}$, then the following connection appears (Anikeichik, Kinzhagulov \& Fedorov, 2016):

$$
T_{N}=T_{1} N^{-M}
$$

where, $\mathrm{M}$ is a value characterizing the labor intensity decrease rate.

The number of possible communication forms between the change in the labor costs volume and the change in the factors of the normalized planning and accounting unit and analogue is limited to three, according to which the calculation formulas for particular comparability coefficients have the form (Bokov, \& Podolsky, 2015):

$$
\begin{aligned}
& K_{1}=\prod_{j=1}^{J}\left(\frac{P_{j}}{P_{a j}}\right)^{\alpha j} \\
& K_{2}=\sum_{j=1}^{j}\left(\frac{P_{j}}{P_{a j}}\right)^{\beta j} \\
& K_{3}=\frac{\sum_{j=1}^{j}\left(\gamma_{j} P_{j}\right)^{b_{j}}}{\sum_{j=1}^{j}\left(\gamma_{j} P_{j a}\right)^{b_{j}}}
\end{aligned}
$$

where, $P_{j}, P_{a j}$ are j-th factors of the normalized planning and accounting unit and equivalent, respectively;

$\alpha_{j}, \beta_{j}, \gamma_{j}$ are regulatory comparison indicators, quantitatively characterizing the factors influence degree on changes in the labor costs volume;

$j=\overline{1, J}$ is a factor's counting number;

$b_{j}=\{-1,1\}$ is a parameter characterizing the influence direction of the $\mathrm{j}$-th factor changes on the labor costs volume changes.

For $P_{j}$ factors included in formulas (2), (3), (4), the acceptable values range is determined by the inequality (Anikeichik, Kinzhagulov \& Fedorov, 2016):

$$
0,5 \times P_{a j} \leq P_{j} \leq 1,5 \times P_{a j}
$$

\section{Discussion}

The procedure for the research implementation on products and their components creation (in the field of production and military equipment) in the framework of R\&D is based on the following regulations use (Dmitriev \& Novikov, 2019):

- GOST 2.102-68 UDDS (Unified design documentation system). Types and completeness of design documents.

- $\quad$ GOST 2.106-96 UDDS. Text documents.

- GOST 2.119-73 UDDS. Preliminary design.

- GOST 2.120-73 UDDS. Technical project.

- GOST 2.501-88 UDDS. Accounting and storage rules.

- GOST 2.503-90 UDDS. Modification Rules.

- GOST 2.902-68 UDDS. Procedure for verification, approval and confirmation of documentation.

- $\quad$ GOST P 2.903-96 UDDS. Document delivery rules.

- GOST PB 2.905-97 UDDS. Rules for the design and technological documentation implementation for a special period. 
Within the framework of a specific study, let us consider the experimental-statistical method for determining the comparison normative indicators and the assessments expert method. When using the experimental-statistical method for determining comparison indicators, the development objects number in the corresponding classification group of the catalog should be at least two $M \geq 2$. To determine the comparison indicators $\alpha_{j}, \beta_{j}$ an auxiliary indicator $\alpha_{j}^{t}$ is calculated according to the formula (Yashin, \& Grigoryan, 2015):

$$
a_{j}^{t}=\frac{\sum_{i=1}^{M} \ln N_{i}}{\sum_{i=1}^{M} \ln P_{j i}}
$$

where, $N_{i}$ is a labor costs volume for the i-th development object of the catalog's classification group;

$P_{j i}$ is the planning-accounting unit's $\mathrm{j}$-th factor related to the $\mathrm{i}$-th development object of the catalog's classification group;

$i=\overline{1, M}$ is a development object's counting number of the corresponding catalog's classification group.

The method of expert assessments allows solving various scientific, technical and economic problems effectively. It is necessary to determine the performed research components, which can be both deterministic and stochastic. To assess the labor intensity, the expert, determining the work duration, also has to set a specific number of certain qualification performers, which will allow obtaining the labor intensity corresponding values: $\mathrm{T}_{\min }$ is the minimum possible, $\mathrm{T}_{\mathrm{m} . \mathrm{p}}$ means the most probable and $\mathrm{T}_{\max }$ is the maximum possible. Based on these values, the expected labor intensity value, the expectation and deviation $\delta^{2}$ are estimated. Using a three-valuation system (Novikov, 2019):

$$
T_{E}=\frac{T_{\min }+4 T_{\text {m.p. }}+T_{\max }}{6}
$$

The value of the expert method is, firstly, in that it reveals the implicit features of the tasks set in the research project, and the comprehensive information necessary for making the right decision is systematized. However, expert evaluation, in turn, is characterized by errors that experts can make during the examination, first of all, systematic errors, which are characterized by a stable positive or negative deviation from the true value, and secondly, random errors, when the values given by experts are characterized by a large dispersion. Thus, the currently used methods of rationing the research labor intensity are characterized by errors (Abramova, Abramov \& Kornilova, 2015).

In case when the norming goal is to determine the labor costs standard volumes for development as a whole, two approaches to solving this problem are possible. The first approach is based on the use of integrated standards at the stages and steps. Stages, steps in this case are the objects of standards development. The stages' and steps' composition of the standardized development determines the standardization objects nomenclature. The enlarged standards are characterized by low accuracy and can only be used for approximate calculations of the labor costs volume for the planned development. The second approach requires the development of detailed execution plan (DEP) for development. The standards development objects are the planning and accounting units of the aggregation level "Procedure" or "Work". Such standards use allows more accurately than in the first case, estimate the planned labor costs volume of for development.

The labor intensity (LI) of prototype designing (D) and manufacturing, its completion after preliminary testing, etc., far exceeds the manufacturing labor intensity of the same product, which has already been put into production, and which has finally worked out the design and manufacturing technology. Moreover, during the development, technological documentation is developed in the route form and in the volume minimally necessary for production. Therefore, in the previously presence of similar works, it is possible to calculate the labor costs using the comparative method (Bokov, \& Podolsky, 2015):

- choose the closest analogue, determine the development price;

- transform the analogue's development price into the current year manufacturing price;

- forecast an increase in the development price, taking into account the new development's complexity and novelty;

- determine the price of the development stages.

For all the work, costs calculation will depend on the total development cost and averages (Durnev \& Zhdanenko, 2013):

- preliminary design + technical project $=10 \%$;

- development of design documentation $=15 \%$; 
- $\quad$ production of models and prototypes $=60 \%$;

- $\quad$ tests $=10 \%$;

- development of design documentation adjustment $=5 \%$.

The price of tests, depending on their volumes, can be much higher, and the manufacture of prototypes is lower, especially if they are based on existing developments.

\section{Results}

The labor intensity calculations by the method described above are easily automated, which allows to focus on the source data preparation. The results of the technique application in practice indicate a high accuracy in establishing the labor intensity normative values, over $92 \%$ of which deviate from the actual labor costs values by only $6-8 \%$. It can also be used in other scientific and thematic areas of $\mathrm{R} \& \mathrm{D}$, but this requires some adaptation to the labor processes content and organizational and technical conditions (Anikeichik, Kinzhagulov \& Fedorov, 2016).

The quality of the determined standard values depends on the source data accuracy. So, the normative labor intensity of conducting applied research and basic research, obtained using expert methods, as practice has shown, is actually determined with an error of $\pm 25-35 \%$. When using experimental statistical methods, the error is $\pm 10-25 \%$, and when applying analytical methods $\pm 15 \%$ or less in the case of the full amount of input information. One should use this provision while assessing the source data quality and choosing a method for determining the normative labor intensity.

This methodology for norming research labor costs is intended to determine research labor cost standards and calculate on their basis the standard labor costs volumes for planned research and planning and accounting units in their composition. It is based on a scheme of normative labor costs volume determining algorithm for a standardized object. In the practical implementation of the above algorithm, it should use a package of specialized programs necessary for the automated preliminary value calculation of the development labor intensity with a different uncertainty level and the range of its possible changes.

The choice of planning and accounting units to be standardized, the objects' range formation of standardization for research have to necessarily depend on the norming goals and include (Novikov \& Veas Iniesta, 2019):

- $\quad$ R\&D norming as a whole;

- $\quad$ stages' and steps' norming;

- individual works and procedures norming;

- regulatory framework formation.

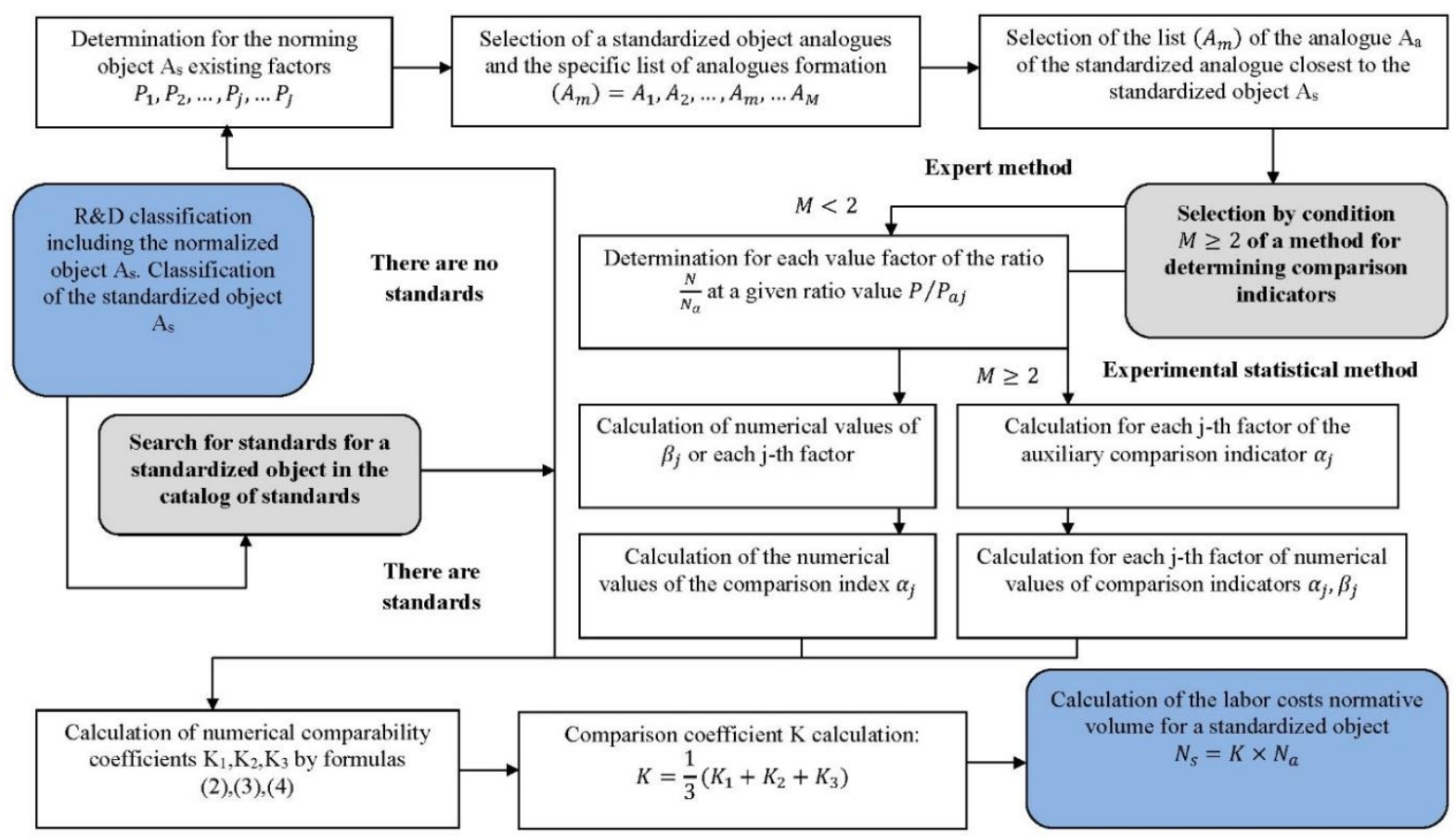

Figure 2. Algorithm scheme for determining the labor costs normative volume for a standardized object 


\section{Conclusions}

The main approaches to R\&D cost determining are repeated in various methods and imply the use of mainly costing methods and various methods using analogues, they are comparative, market. The main features of R\&D cost assessing arise from the research work nature; this is a high uncertainty degree of the result obtained and the difficulty of directly comparing cash costs and the results obtained during R\&D. The costs' classification is regulated by many normative acts, but the standards' identification that determine their level is a rather complicated task that requires additional justification. One of the directions for increasing the $R \& D$ cost determining efficiency is the further improvement of the legislative and normative-methodological framework for conducting this assessment, creating incentives for work performers to reduce costs at the required R\&D quality level, for example, by saving for them some of the resulting savings. For the state orders sphere, it is advisable to create information resources containing, also statistical information about the price level. In this area, it is necessary to improve financial control and legislation regulatory and organizational foundations regarding liability for unreasonably overpricing a state contract.

Knowing the labor intensity, duration and cost of future R\&D allows drawing up optimal work plans for research organizations and, as a result, achieving high economic performance. Further considered methods development is associated with the automated system development for planning and monitoring the scientific work performing process carried out according to the industry's order.

\section{References}

Abramova, I. G., Abramov, D. A., \& Kornilova, A. S. (2015). Economics of R\&D: training manual. Samara: Publishing House of Samara State Aerospace University.

Anikeichik, N. D., Kinzhagulov, I. Yu., \& Fedorov, A. V. (2016). Planning and management of R\&D. Tutorial. St. Petersburg: ITMO University.

Avdeeva, I. L., Polyanin, A. V., \& Golovina, T. A. (2019). Digitalization of industrial economic systems: problems and consequences of modern technologies. News of Saratov University: Series of Economics, management, law, 19(3), 238-245.

Bokov, S. I., \& Podolsky, A. G. (2015). Principles for assessing the research labor intensity carried out in the interests of electronic component base development. Armament and Economics, 1(30), 84-93.

Dmitriev, O. N., \& Novikov, S. V. (2019). Concept of state management doctrine. Amazonia Investiga, 8(22), 238-246.

Durnev, R. A., \& Zhdanenko, I. V. (2013). R\&D labor intensity assessment: some results of the scientific work norming. Modern high technologies, 12, 40-48.

Novikov, S. V. (2019). Conceptual Analysis of Aviation Infrastructure. Russian Engineering Research, 39(4), 354-356.

Novikov, S. V., \& Veas Iniesta, D. S. (2019). Analysis of development trends in the innovation industry of the Russian Federation. Amazonia Investiga, 8(19), 298-307.

Yashin, N. S., \& Grigoryan, E. S. (2015). The methodology of strategic sustainability of the enterprise. Bulletin of the Saratov State Socio-Economic University, 1(55), 18-22. 